\title{
Making Cross-company Information Available in the Conceptual Phase
}

\author{
Patrik Boart $^{1}$ and Bengt-Olof Elfström ${ }^{2}$ \\ ${ }^{1}$ Luleå University of technology, Patrik.Boart@ltu.se \\ ${ }^{2}$ Luleå University of Technology, Bengt-Olof.Elfstrom@volvo.com
}

\begin{abstract}
In new business-to-business relations within the aerospace industry, companies join together in partnership to perform product development, taking full responsibility for their product during its entire life cycle. This paper describes a method on how these downstream effects can be simulated in a cross-company collaborative situation. A case study was conducted where a jet engine component manufacturer and a tool manufacturer used each other's expertise in a collaborative approach to make "holes" in a jet engine component. Ten conceptual jet engine frames were collaboratively evaluated within two working days. The distributed engineering environment creates a new situation for the partnership companies by allowing them to work efficiently within the activities that have been incorporated into the distributed engineering environment. Downstream effects of the overall system can then be evaluated already in the conceptual phase, thus allowing the partners to design the life cycle properties of their common product.
\end{abstract}

Keywords: Cross-company information, cross-company availability, cross-company concept.

\section{INTRODUCTION}

The main driving force for new products is to contribute to a sustainable society. One solution is to then buy the function of the product instead of the product itself, meaning that the product provider will be responsible to deliver the function through the life cycle of the product. The product provider will then own the product and be responsible for all costs to develop, manufacture, support and continuously upgrade the product. A large risk will then be transferred from the customer to the function provider. A trend is for the customer to also want to buy larger solutions provided by many companies in a network. Hence, the companies will be forced to cooperate as early as possible in the product develop phase to minimize the risks. A development process supported by very fast simulation tools will be critical to the concept phase to achieve many iterations and allow the possibility to optimize over the total system. This new development process will be performed in a distributed engineering environment.

This trend needs a holistic product perspective where products and services are seen as parts of a market offer. It will have important implications to manage product and service development and to communicate between marketing and engineering [1-2]. To address a typical holistic product in business-to-business relations within the aerospace industry, a particularly high-tech business, working on long lead times and requiring huge capital sums, is using the term functional product (total care product) to explain their particular product development situation [3]. In these new business-to-business relations companies joins together in partnership to perform product development, thereby taking full responsibility for their product during its entire life cycle.

The European program VIVACE [5] (Value Improvement through a Virtual Aeronautical Collaborative Enterprise) includes an Aeronautical Collaborative Design Environment to allow partners to develop products where associated Processes, Models and Methods can be shared. This is one step towards the support needed to design an overall system towards the needs of the partnership during the life cycle of the offer and the products (low life cycle cost, low production cost, etc.).

During the early phase of product development, a large part of the product's life cycle is defined [1]. To optimize the total product system between aerospace partners in the conceptual phase, there is a need to perform several iterations is needed, at least 10 within 2 days fulfilling airworthiness requirements.

Very few tools that support the conceptual phase of product development exist [7], due mostly to imprecise and incomplete design requirements and constraints during this early phase of the product's life cycle [8]. Still, if there were 
tools that would allow partners to share everything and perform fast iteration over the total system, this would have to be done without the exchange of company critical core knowledge assets.

\section{CROSS-COMPANY COLLABORATION}

Collaboration within a single company during product development is a difficult process [9] and will even be more complicated between companies with the problem of acquiring and accessing information and knowledge, coordination problems due to different decisions levels, etc. To solve these problems, a number of authors suggest different tools and methods that helps with the sharing of information and knowledge between companies, see Table 1 .

\begin{tabular}{|llll|}
\hline Cross company collaboration & Year & Authors \\
\hline Methods & Description & Bin et al. [10] \\
\hline $\begin{array}{l}\text { Using } \\
\text { Features }\end{array}$ & $\begin{array}{l}\text { "This paper presents a methodology in which the knowledge of design intents and } \\
\text { change requests is communicated unambiguously cross collaboration partners } \\
\text { through features." }\end{array}$ & 2003 & \\
\hline $\begin{array}{l}\text { Virtual } \\
\text { meetings }\end{array}$ & $\begin{array}{l}\text { presents "an initial TeamSpace prototype that supports asynchronous meeting } \\
\text { management seamlessly integrated with capture and access of synchronous } \\
\text { distributed meetings. The captured synchronous data is integrated with other related } \\
\text { information in TeamSpace, enabling users to efficiently gain knowledge of both }\end{array}$ & & Geyer et al. [11] \\
& $\begin{array}{l}\text { current and past team activities." } \\
\text { "Investigation of instant messaging use for work-related activities in a commercial }\end{array}$ & 2002 & Hansen et \\
messages & setting." & al. \\
\hline $\begin{array}{l}\text { Web } \\
\text { based } \\
\text { services }\end{array}$ & $\begin{array}{l}\text { "Fundamental to the FIPER project is its web-based distributed software } \\
\text { architecture. FIPER federates processes, tools, methods, documents, or knowledge } \\
\text { bases and data into a dynamic, distributed Intelligent Master Model with its } \\
\text { underlying services." }\end{array}$ & Röhl et al. [13] \\
\hline
\end{tabular}

Tab. 1. Cross-company collaboration methods.

One aspect that makes collaboration between companies more difficult is the need to protect company assets, such as business strategies, engineering knowledge, etc. This can be handled with a "need-to-know" basis, where each designer is informed with the minimum level of information to get the task done. Two articles in Table 1 take advantage of this strategy with two different approaches. Cera et al. [11] describe a method where 3D models are geometrically partitioned, which is used to create multi-resolution mesh hierarchies that obscure, obfuscate, or remove sensitive material from the view of users without the appropriate permissions. Larsson et al. [12] describe how a modular analysis model allows a black box approach, where models are not to be transferred from the company. These modules are then invoked by a call procedure, not as computationally efficient as the server invoke, but a viable solution to keep company specific models a secret.

\begin{tabular}{|llll|}
\hline Distribution of engineering activities cross-company & Year & Authors \\
\hline Methods & Description & Cera et al. [14] \\
\hline $\begin{array}{l}\text { Role-based } \\
\text { viewing }\end{array}$ & "This paper has presented a new technique, role-based viewing, for collaborative & 2004 & \\
& and risks incurred by multi-organizational collaboration can be reduced." & & \\
\hline $\begin{array}{l}\text { Modular } \\
\text { Multibody }\end{array}$ & "A method, or tool, that supports web-based multibody dynamic simulation, in a & 2002 & Larsson et \\
dynamic & modular way, is proposed and developed. It allows parallel development of & al. \\
$\begin{array}{l}\text { Simulation } \\
\text { process }\end{array}$ & & {$[15]$} & \\
\end{tabular}

Tab. 2. Distribution of engineering activities cross-company.

\section{METHOD}

During the early phase of product development, a large part of the product's life cycle is defined [1], making the conceptual phase a critical part of the functional product development process. This section will present a method to increase the information available in a cross-company conceptual phase. The method will answer the following research questions:

Computer-Aided Design \& Applications, Vol. 3, No. 6, 2006, pp 675-682 
1. How can a creative distributed environment be able to exchange complete information that will allow partners to optimize their part of the product and thus allow optimization of overall product life cycle properties?

2. How can total systems with at least 10 iterations within 2 days of fulfilling airworthiness requirements be optimized?

3. How can information be exchanged without an exchange of critical knowledge assets?

The method will consist of the following steps:

1. Establish business relationships between the companies

2. Establish engineering relationships in the product development process to optimize the design intent and its solutions

3. Transferring information to the conceptual phase

4. Identify where in the concept development process information needs to be shared

5. Identify which type of information needs to be shared

6. Identify how to share the information without exchanging critical core knowledge assets

The first two steps of the method are not discussed in this paper because they are more related to relationship management and are therefore not the main subject of this paper. The method is detailed in steps 3 to 6 .

\subsection{Transferring of Information to the Conceptual Phase}

Reusing earlier knowledge from earlier projects is the base for developing products in the conceptual phase. The quality of the work can be further improved if all life cycle phases of the new product can be simulated. Boart et al. [6] describe a method using a system support to transfer downstream knowledge to the conceptual phase. Downstream information is made available by simulating the downstream effects based on conceptual decisions; see Fig. 1. Working with these types of automated systems where critical core knowledge of the company is built in makes it a vulnerable source that needs to be kept safe. Still, coupling these systems with other partners would increase the amount of available information in the conceptual phase and make it possible to optimize over the total system.

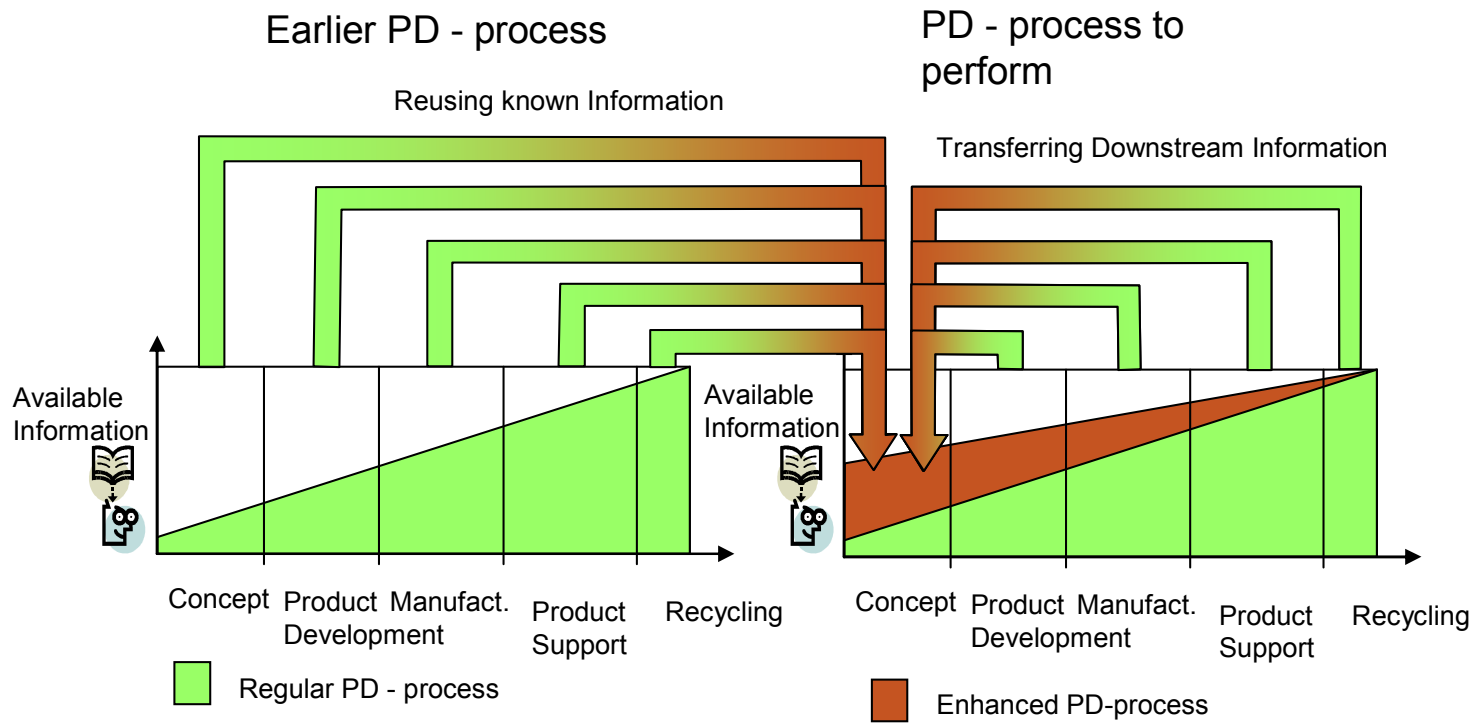

Fig. 1. Transferring downstream information to the earlier phase.

\subsection{Information Exchange without Exchange of Critical Core Knowledge Assets}

Figure 2 shows two companies involved in a partnership to develop a product. Each company has its own process, information technology, data and information resources, and knowledge. What is shared and how the partners are integrated with each other is a contractual agreement that needs to be determined before cross-company collaboration can be performed. 
Company A

Partner

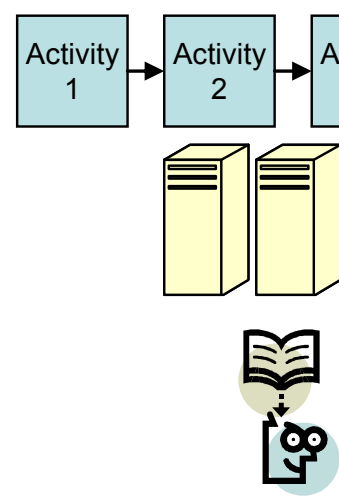

Relation

Process

Information

Technology

Data/

Informtion/ Knowledge
Company B

Partner
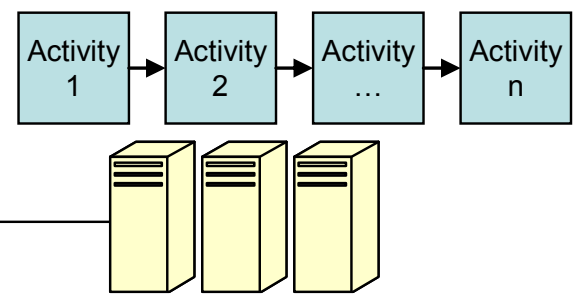

Fig. 2. Two companies involved in a partnership developing a product.

3.2.1 Identify where and which Information Needs to be Shared

By identifying the minimum level of shared needed information, the partners can perform their task and simultaneously protect the critical core knowledge assets of each partner, see Fig. 3. The first step is to identify where in the conceptual process information needs to be shared. This is performed through several meetings and workshops where the partners identify and explain for each other which information they need to perform their tasks.

\section{Company A}

\section{Company B}

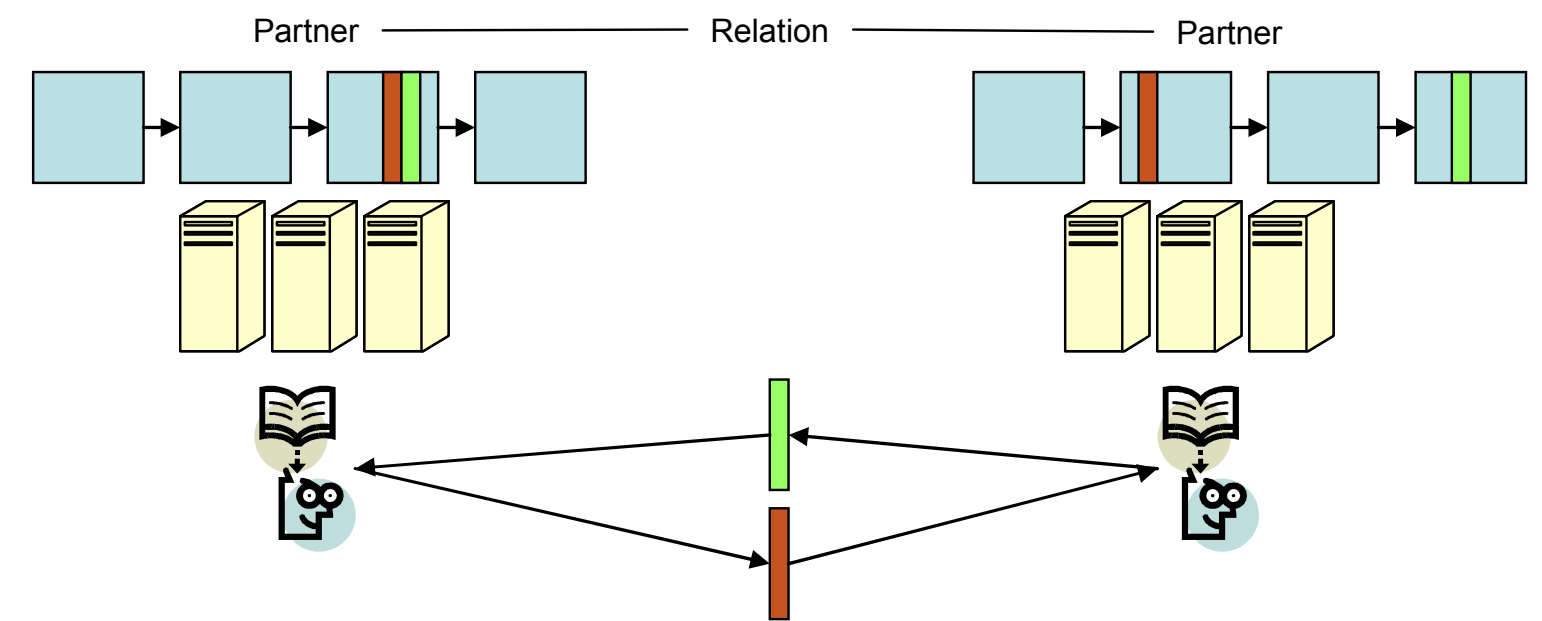

Fig. 3. Partner informed with minimum level of information to get the task done.

\subsubsection{Identify how to Share the Information}

When the shared information is identified, the partners need to decide how to exchange this information. The partners will decide on which format the information is to be exchanged as well as security issues to send the information between each company.

\section{CASE STUDY}

To test this approach a case study was conducted between a jet engine component manufacturer and a cutting tool manufacturer. The main idea was to try to use each partner's expertise in a collaborative approach to make "holes" in a jet engine component, see Fig. 4.

Computer-Aided Design \& Applications, Vol. 3, No. 6, 2006, pp 675-682 


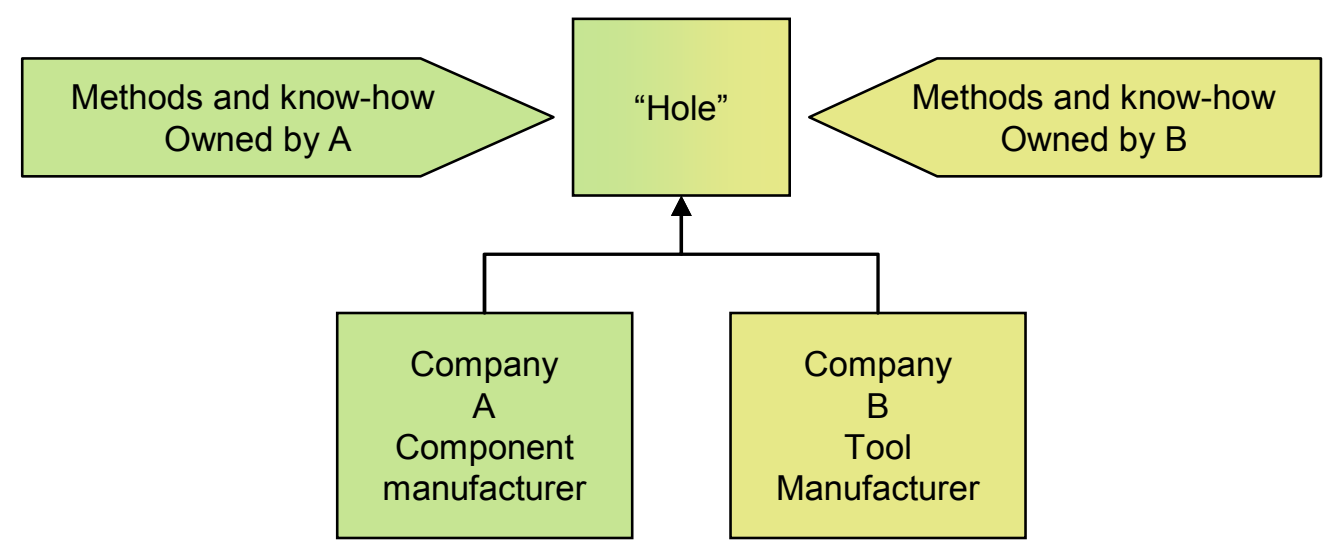

Fig. 4. The picture describes a collaborative approach to create holes between a jet engine component manufacturer and a tool manufacturer.

In one activity of the jet engine component manufacturer, how the drilling operation will affect the component needs to be analyzed. To perform this activity the drilling force needs to be calculated, depending on the material, size of the hole, and drilling time. The expertise to calculate the drilling force is found at the tool manufacturer. Both companies have developed tools that can quickly simulate how their products will behave depending on a number of parameters. Boart et al. [16] describe the approach to create such a tool and this method allows the pre-processing activity to be performed for 10 conceptual jet engine frames within 2 working days, see Fig. 5.
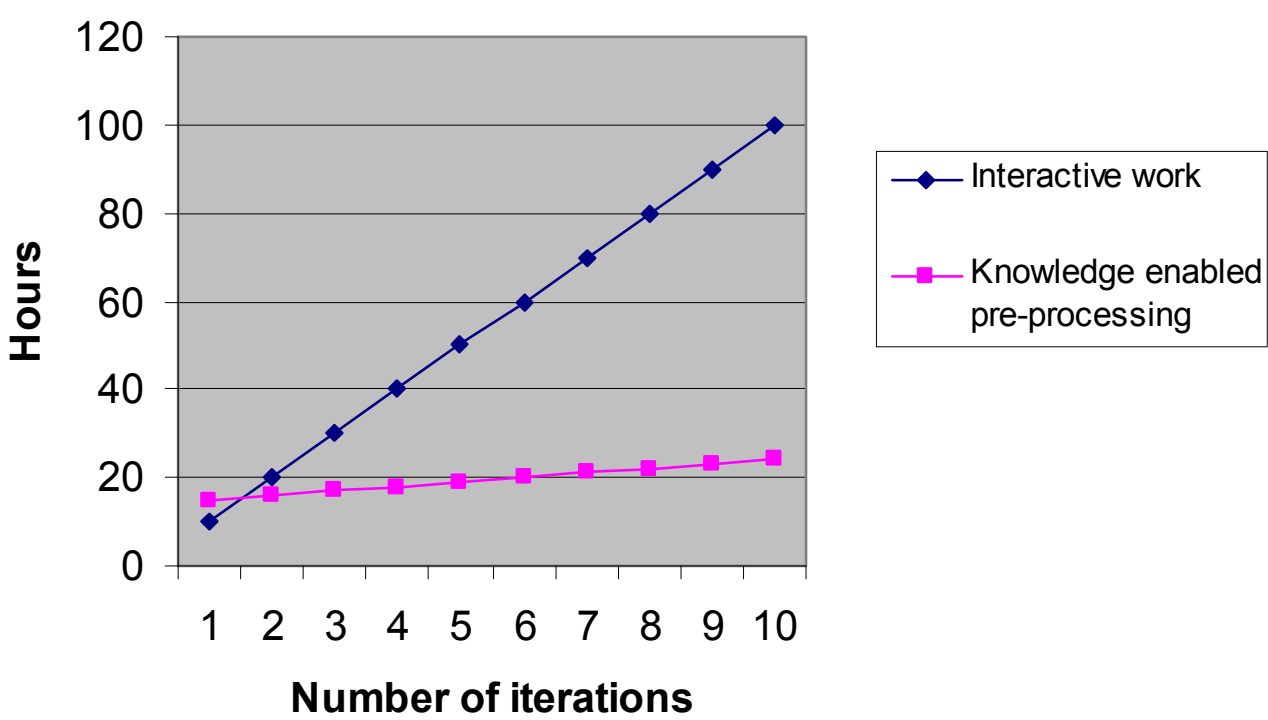

Fig. 5. Graph describing the time saved in each iteration between working interactively compared to using the knowledge enabled pre-processing tool [16].

In this case the information to be shared from the component manufacturer was material, hole size, drilling depth and stiffness matrix. In return, the tool manufacturer could calculate the minimum drilling time and forces generated and check if the hole could be manufactured within certain tolerances. With this information, the partners agreed to join their systems to allow this information to be transferred between each other.

To transfer the behavior around the area to be drilled, super elements were used to extract the stiffness matrix. Figure 6 shows the surface model (blue model) used by company A to generate a mesh (green model). The entire model is meshed except the area to be drilled. Super elements are then coupled to the boundaries of the area to be drilled, see Fig. 7. By using symmetry the stiffness matrix is then calculated and transferred with the information about material, 
hole size, and drilling depth to company B. Notice that the geometric representation of company A concept is unknown to company $\mathrm{B}$, except the boundary behavior that is transferred with the stiffness matrix representation.

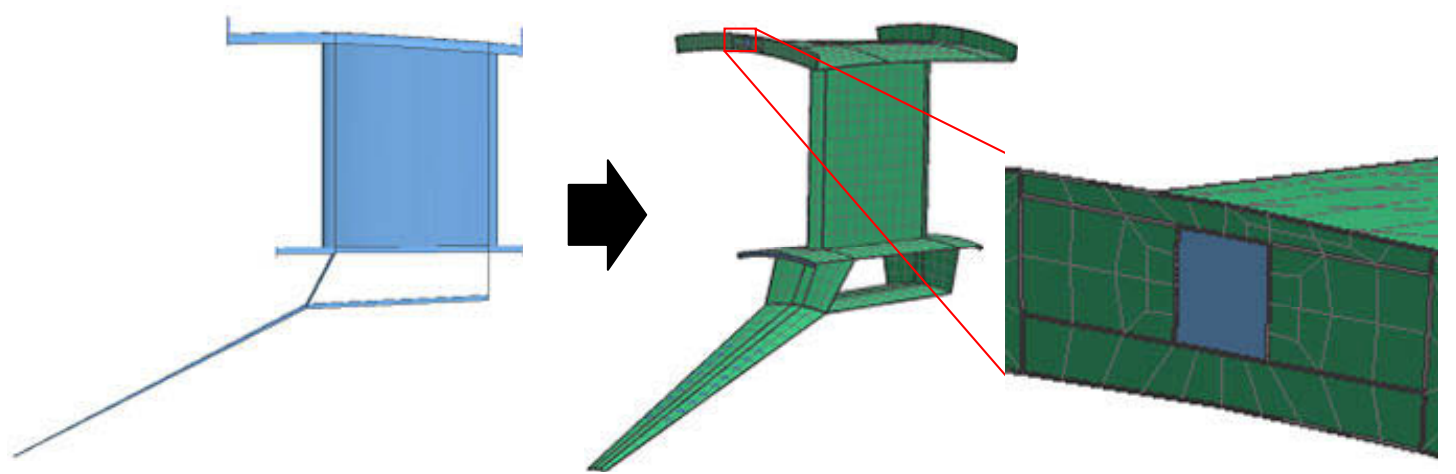

Fig. 6. The blue surface model is used to generate a mesh. The entire model is meshed except the area to be drilled.

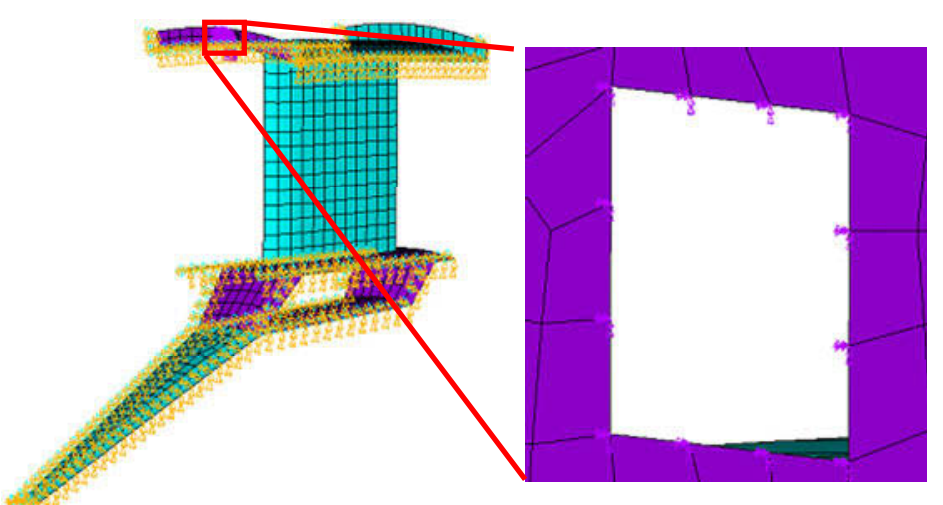

Fig. 7. Symmetry is used and the stiffness matrix is calculated by using super elements coupled to the boundaries around the area to be drilled.

A model representing the area to be drilled is generated and meshed at company $\mathrm{B}$, see Fig. 8. The super elements (stiffness matrix) are coupled to the mesh along the boundary edges and the calculated force of the drilling operation is applied. The model is solved and the displacement of the area is calculated. From the calculated displacements the tolerance fulfillment is analyzed.
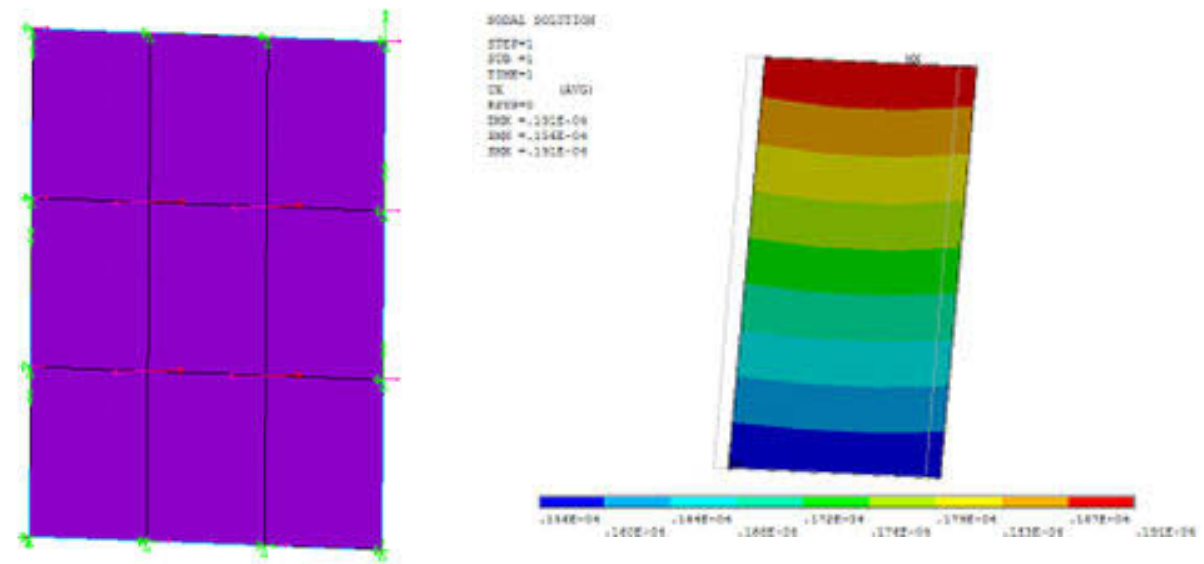

Fig. 8. The super elements are coupled to the mesh along the boundary edges and the calculated force of the drilling operation is applied. The model is solved and the displacement of the analysis is used to check tolerance fulfillment of the hole to be drilled.

Computer-Aided Design \& Applications, Vol. 3, No. 6, 2006, pp 675-682 
By coupling the systems of the component manufacturer with that of the tool manufacturer and only share information about material, hole size, drilling depth, stiffness matrix and force, the partners could sit together and perform different concept evaluations without any collaborative delays. This allowed both partners to optimize the overall system by exchanging both component and tool parameters. The component manufacturer's system starts to define the design of their component. The model is then automatically pre-processed, and the data specified and required by the tool manufacturer is transferred over a secure web interface. From the information received, the tool manufacturer can analyze the effect of the drilling operation on the drilling area. The displacements generated by the drilling operation is analyzed and communicated back to the component manufacturer.

\section{RESULTS}

The effect of the drilling operation for 10 conceptual jet engine frames is evaluated within 2 working days. The method used in the case study enables two companies to only communicate the necessary information needed to simulate the engineering process on both sides. This allows both companies to cooperate in an early design phase and simulate the downstream effects of the overall system without exchanging engineering knowledge. Five concepts were found to fulfill the requirements concerning the holes, see Table 3.

\begin{tabular}{|llll|}
\hline Concept & Within specified drilling time & Within tolerance & Drill operation affect on component \\
\hline 1 & Yes & No & - \\
\hline 2 & Yes & Yes & OK! \\
\hline 3 & No & - & - \\
\hline 4 & Yes & Yes & OK! \\
\hline 5 & Yes & Yes & OK! \\
\hline 6 & No & - & - \\
\hline 7 & Yes & No & - \\
\hline 8 & Yes & Yes & OK! \\
\hline 9 & Yes & No & - \\
\hline 10 & Yes & Yes & OK! \\
\hline
\end{tabular}

Tab. 3. Evaluation on component affect of drilling operation.

The results of the case study show that our approach to answer the research questions by the suggested method was successful.

To build the relationship needed to run the process of identifying where, which and how is rather time consuming. Months are needed to just arrange meetings, and discuss and plan the project to set up this system. This problem also exists in development projects where access to the necessary people is not always fast and easy. This is where the benefits of the extra time spent to arrange this form of cooperation is gained back when instant access to information is achieved cross-company. The actual time to identify where and which information needs to be shared were straightforward when the relationship and partnership plan was set and every one understood what could and could not be shared. The second part that needed some extra time was to define how to set up the system to allow cooperation. The systems to perform the activities in each company need to first be developed. Finding an efficient and safe way to link the systems globally is the next step. The efficiency aspect of global cooperation has been left for others to investigate, and the focus here has been the actual cooperative benefits with this type of cross-company collaboration.

The results show that it is possible to create a globally distributed environment able to exchange the information needed that allows partners to not only optimize their part, but also the overall product life cycle. This is done by allowing the partners to iterate over the total system several times, and testing out the effects of different decisions made by either partner. Since the system by itself protects company critical knowledge assets, the interaction becomes smooth and fast.

Using these tools correctly will increase efficiency when transferring information and knowledge, though it is not optimal before all information or knowledge is received instantly when asked for. The idea with a partnership is that this form of collaboration between two companies can reduce information and knowledge sharing problems or perhaps eliminate them. 


\section{CONCLUSION}

A case study was conducted where a jet engine component manufacturer and a tool manufacturer used each other's expertise in a collaborative approach to make "holes" in a jet engine component. Ten conceptual jet engine frames were collaboratively evaluated within two working days. The distributed engineering environment creates a new situation for the companies in partnership allowing them to work efficiently within the activities that have been incorporated into the distributed engineering environment. The downstream effects of the overall system can then be evaluated already in the conceptual phase, allowing the partners to design the life cycle properties of their common product without exchanging unnecessary information.

With a collaborative system the time to perform the cross-company process becomes a system efficiency problem instead of a collaborative issue (access to information and people globally). This makes it possible to define partner strategies and arrange cross-company collaborative systems to exchange only the information to perform the common interest of the partnership.

\section{REFERENCES}

[1] Brännström, O. and Elfström, B.-O., Market offer concept development - using a post industrial product construct in practice.

[2] Brännström, O, and Elfström, B.-O., Integrated product \& service offerings - their rationale and creation.

[3] Alonso-Rasgado, T., Thompson, G. and Elfström, B.-O., The design of functional (total care) products, Journal of Engineering Design, Vol. 15, NO. 6, 2004, pp 515-540.

[4] VIVACE

[5] Kusiak, A., Concurrent Engineering: Automation, Tools and Techniques., New York, Wiley, 1993, ISBN: 0-47155492-8.

[6] Boart, P., Nergård, H., Sandberg, M. and Larsson, T., A Multidisciplinary design tool with downstream processes embedded for conceptual design and evaluation, International Conference on Engineering Design, Melbourne, 15-18 August, 2005.

[7] Wang, L., Shen, W., Xie, H., Neelamkavil, J. and Pardasani, A., Collaborative conceptual design-state of the art and future trends, Computer-Aided Design, vol. 34, No. 6, 2002, pp 981-996.

[8] Hsu, W. and Liu, B., Conceptual design: issues and challenges, Computer-Aided Design, Vol. 32, 2000, pp 849-850.

[9] Crabtree, R. A., Fox, M. S. and Baid, N. K., Case Studies of Coordination Activities and Problems in Collaborative Design, Research in Engineering Design, Vol. 9, 1997, pp 70-84.

[10] Bin, S., Zengzhi, L., Qinrong, F. and Feng, L. W., Using Features as the Knowledge Carrier for cross company collaboration and Change Management - A design methodology for compressing lead-time from plastic part design to mold making, International Journal of CAD/CAM, Vol. 3, No. 2, 2003, pp 43-50.

[11] Geyer, W., Richter, H., Fuchs, L., Frauenhofer, T., Daijavad, S., and Poltrock, S., A Team Collaboration Space Supporting Capture and Access of Virtual Meetings, Proceedings of the 2001 International ACM SIGGROUP Conference on Supporting Group Work, ACM press, 2001, pp 188-196.

[12] Hansen, M. K. and Damm, H. G., Instant Collaboration, Using Context-Aware Instant Messaging for Session Management in Distributed Collaboration Tools, Proceedings of the second Nordic conference on Humancomputer interaction NordiCHI '02, Publisher: ACM Press, October 19-23, 2002, pp 279-282.

[13] Röhl, P. J., Kolonay, R. M., Irani, R. K., Sobolewski, M. and Kao, K., A Federated Intelligent Product Environment, 8th AIAA/USAF/NASA/ISSMO Symposium on Multidisciplinary Analysis and Optimization, Long Beach, CA, September 6-8, 2000.

[14] Cera, C. D., Kim, T., Han, J. and Regli, W. C., Role-based viewing envelopes for information protection in collaborative modeling, Computer-Aided Design, Vol. 36, 2004, pp 873-886.

[15] Larsson, T. and Larsson A., Web-based Multibody Dynamics using Distributed Simulation Modules, Annals of 2002 International CIRP Design Seminar, Hong Kong, 16-18 May, 2002.

[16] Boart, P., Andersson, A. and Elfström, B.-O., Knowledge Enabled Pre-processing for structural analysis, $1^{\text {st }}$ Nordic Conference on Product Lifecycle Management - NordPLM'06, Göteborg, January 25-26 2006. 